\title{
Challenges faced by the LGBTQ community- A comparative study between India and
} Australia.

\section{Dr. Shilpa Sharma,}

Assistant Professor, Institutional Affiliation: Symbiosis Law School, Nagpur. (affiliated to Symbiosis International Deemed University, Pune.)

Article History: Received:11 January 2021; Accepted: 27 February 2021; Published online: 5 April 2021

\begin{abstract}
The challenges of sexual minorities are often underscored in the world and taken a backseat. But to effectively use Gender mainstreaming as a base for policy work, we need to change that. This article broadly investigates the challenges faced by the LGBTQ community in a comparative format. Giving due weightage to the global perspective, this article tries to analyse the challenges faced by a developing country, India and a developed country, Australia. The aim of the study, simply speaking, is to derive at what stage are we in the liberalization of LGBTQ compared to a developed country, what are the historical factors that have influenced the progress, if any. The researchertook up this topic because as a citizen in this democratic country, it is incredibly concerningto hear about the challenges that the LGBTQ have to face and a positive change in the country's mindset is the need of the hour. The researcher has employed doctrinal methodology in the research paper to arrive at the results. After carefully dissecting the historical background, the challenges and the subsequent suggestions of the LGBTQ community in India and Australia, the researcher has arrived at some results. India, currently, is at the initial stages of reforms in the LGBTQ community as compared to Australia and some of it can be attributed to the different perspectives of a culturally and religiously rich India. In terms of awareness and acceptance rate, India is quite low. Most of the challenges faced by the community are due to lack of awareness and knowledge. But to give credit when it's due, India has come a long way and fought a hard battle. It isn't going to be easy in the coming future but what we need is an educated and upstanding youth community. The reforms will follow accordingly.
\end{abstract}

Keywords: Gender Mainstreaming, Challenges, LGBTQ community, social exclusion and discrimination, sexual minorities.

\section{Introduction}

Over the years, human rights and 'equality for all' movement has been gaining momentum at a rapidly increasing pace. Keeping this in mind, Gender mainstreaming has become a very integral part of the process to promote general equality all around the globe across various countries. Council of Europe (2016) defined Gender mainstreaming asthe (re)organisation, improvement, development and evaluation ofpolicy processes, so that a gender equality perspective is incorporated in all policies at all levelsat all stages, by the actors involved in policy-making. Therefore, it is incredibly relevant in this day and age to research more about it.

While equal rights movement has been gaining traction, some groups like the LGBTQ community are still being deprived of basic human rights. And these violations of LGBTQ rights have profound effects. Therefore, legal framework in absolutely necessary. In this context, the paper will delve deeper into one of its sub themes i.e., Challenges of Sexual Minorities and Special Groups, wherein keeping in mind the Global Perspective of the paper, there will be a comparative study between India, a developing country and Australia, a developed country on challenges faced by the LGBTQ community. The LGBTQ stands for Lesbian, Gay, Bisexual, Transgender, Queer or Questioning. These terms are usually used to describe a person's gender identity or sexual orientation (Gay Centre (n.d)). Gay centre defines Lesbian as a women whose enduring physical, romantic, and/or emotional attraction is to other women; Gay as people whose enduring physical, romantic, and/or emotional attractions are to people of the same sex; Bisexual as a person who has the capacity to form enduring physical, romantic, and/or emotional attractions to those of the same gender or to those of another gender; Transgender as people whose gender identity and/or gender expression differs from what is typically associated with the sex they were assigned at birth; Queer as people, particularly younger people, whose sexual orientation is not exclusively heterosexual.This community has faced a lot of backlash and discrimination over the years. While some countries have progressed, others are still stuck in the past. This paper will attempt to understand the challenges faced by them from both a developing and a developed country point of view.

\section{$\underline{\text { International Law }}$}

Around the world, the introduction and growth of LGBTQ movements looks different. While the developed countries enjoy a considerable edge as compared to the developing countries, stigma and discrimination still hangs around like a dark cloud. 
On May 17, 1990, a seed of hope took growth as the World Health Organization removed homosexuality from the list of mental disorders, recognizing it as a natural variant of human sexuality (Graeme Reid, 2017). This incredibly important breakthrough now represents an annual celebration of LGBTQ, known as the International Day Against Homophobia, Biphobia and Transphobia (IDAHOBIT). Owing to this, many LGBTQ movements started in various countries and blossomed from there.

\section{Australia}

The emergence of Gay and Lesbian rights movements in Australia became apparent in the 1960s. In the years that followed, gay rights organizations popped up all round the country. After a lot of struggle, in 1994, the Commonwealth passed the Human Rights (Sexual Conduct) Act 1994 - Section 4, legalising sexual activity between consenting adults (in private) throughout Australia (Human Rights Act, 1994). It was later in 1997 that Tasmania caught up and repealed the law prohibiting gay male sexual conduct. But the fight wasn't over yet. In 1996, Prime Minister John Howard made very clear that he wasn't a big fan of gay rights issue. UN tried to interfere in the matter but Australia ignored it. In August 2004, same-sex marriage was officially prohibited when the Marriage Act 1961 and the Family Law Act were amended in order to define marriage as a "union of a man and a woman to the exclusion of all others, voluntarily entered into for life" (Wikipedia, 2020). Fortunately, the Labour party won the next election and they passed a legislation to remove discrimination against same-sex couples from 85 federal laws relating to areas such as tax, veterans' affairs, social security and health. Later, an amendment was made to the Sex Discrimination Act, making it unlawful to discriminate against lesbian, gay, bisexual, transgender and intersex people (Ben Winsor, 2016). In December 2017, post a survey which resulted in a $61 \%$ yes, the federal Parliament passed a law amending the Marriage Act 1961 to allow same-sex couples to marry (ABC News, 2017). Subsequently, in April 2018, adoption by same-sex couples became legally available in all jurisdictions of Australia.

\section{India}

India has always enjoyed the tag of being a religiously and culturally rich land. Due to this, it has emerged to shape the customs and traditions of our nation quite a lot. Hinduism, the largest religion in India dictated a lot of those customs and traditions. In ancient Hinduism texts, a lot of stances have been taken on the topic, the tone usually being neutral or antagonistic. When the Britishers came to India, they criminalized sexual activities "against the order of nature", including homosexual sexual activities, under Section 377 of the Indian Penal Code, which entered into force in 1861 (Wikipedia, 2021). Even after independence in 1947, homosexuality still remained a criminal offence. In the 1990s, the movement started gaining traction. In 2009, a landmark ruling occurred in the Naz Foundation v. Govt. of NCT of Delhi case wherein they held that treating consensual homosexual sex between adults as a crime is a violation of fundamental rights protected by India's Constitution. (Delhi High Court, 2009). But it was later overruled by the Supreme Court. Finally, on 6 September 2018, the Supreme Court of India ruled that the application of Section 377 to consensual homosexual sex between adults was unconstitutional, "irrational, indefensible and manifestly arbitrary", (Raja Gopal, Krishnadas, 2018) but that Section 377 remains in force relating to sex with minors, non-consensual sexual acts, and bestiality (Pundir, Pallavi, 2018). Yet even after scrapping of Section 377, stigma still persists in the society for LGBTQ community.

\section{Challenges}

While India may have decriminalized consensual sex between gays, in the real sense of the world, it is still quite behind the memo. The people who come out as LGBTQ are majorly shunned by their families, thrown out and degraded. If we talk about acceptance, India is at a very low scale but it's getting there. Australia, on the other hand, is a lot more aware and accepting as compared to India but still the LGBTQ community has to face a lot of bullying and discrimination.

In this section, the challenges faced by the LGBTQ in both the countries will be discussed in detail to measure and understand how different factors have led to different challenges and how in some cases, there is a similarity in their hardships.

\section{India}

1. Honour Killings and corrective therapy: In some parts of rural India, secret honour killings are carried out while in other parts, lesbian woman are often subjected to family-sanctioned corrective rapes, often perpetrated by their own family members (Mint, 2021). This is a particularly inhumane 
practice that the LGBTQ have to face. Many families also force LGBTQ people to undergo corrective therapy, treating their sexual orientation as a disease that can be cured.

2. Lack of Proper Healthcare: The transgender community has to face the worst of it all. In India, the gay and lesbian community has fared a little better than the transgender community. The transgender community face a lot of issues while accessing healthcare services and there have been numerous incidents to suggest inappropriate behaviour and discrimination displayed towards them. Hospitals and medical staff are also sometimes unaware as to how to treat transgender people. The health issues include diseases such as HIV, rectal gonorrhoea, syphilis, rectal chlamydia and various other forms of sexually transmitted diseases (Malavika Rajkumar, 2018). Proper toilet facilities are not available to them, which again infringes upon their basic civil right issues.

3. Acquisition of identity Documents: Another major problem that the transgender community face is acquiring proper identity documents, which can help them to access basic civil rights like right to vote, right to education, etc. This breeds inclusion and isolation which can often lead to feeling of helplessness and anxiety. On top of this, majority of the transgender community is illiterate or less educated due to which they are not able to secure proper jobs and immerse themselves in social, economic and cultural activities (Subhrajit Chatterjee, 2018).

\section{Australia}

As for Australia, a lot of challenges faced by the LGBTQ community are similar, though in moderation. Mental health, bullying, anxiety and depression are just some of the major issues that the LGBTQ community have to go through in their life. A study found that LGBTQ community in Australia are far more likely to be psychologically depressed than non-LGBTQ members (Beyond Blue, n.d.).

1. Lack of Health Rights: In Australia, one of the major challenges is Health rights. Many Medicare and private health insurance do not cover all the treatment costs that transgenders may require to make a transition, such as surgical changes (Liam Elphick, 2019). In some states, the transgenders have to undergo surgery or medical treatment before they can change their sex on their birth certificate. Many of them choose not to or can't afford the treatment.

\section{Common to both India and Australia}

1. Coming-Out Anxiety: Coming out of the closet, often shortened to coming out, is a metaphor for LGBTQ people's self-disclosure of their sexual orientation or of their gender identity (Wikipedia, 2021). Irrespective of the country, coming out is a very important event for LGBTQ. In a conservative country like India, it is often a huge deal and a point of contention among the family members. The anxiety of how their family and friends will react can often incite anxiety and depression.

This problem is faced in Australia too, but comparatively to a lesser degree. While many families are accepting, many are not. They are thrown out of their homes, with no financial support and no career prospects.

2. Psychological Problems: Feelings of not being wanted and discriminatory comments and remarks can lead to isolation, mental health problems and can escalate to suicidal thoughts. Their basic rights are often infringed upon during the course of their daily life. The young transgender community, especially, is subject to a lot of bullying at educational institutions. Verbal and physical attacks are often a common occurrence, directed towards the LGBTQ community.

3. Discrimination at Workplace: They also face a lot of discrimination at the workplace. In India particularly, due to the rigid societal constructs, they are treated differently. This furtheroften lead to unemployment and poverty. In India, at times like these, many of them resort to begging and sex work. As for Australia, the situation is better comparatively, but an unconscious feeling of discrimination does prevail over matters of promotions and acquiring jobs.

4. Lack of awareness among the population: In India, majority are sheltered and unaware of what LGBTQ actually means. This can lead to a lot of mistrust, stigma and discrimination towards the LGBTQ. Most of the population, especially the rural population, relates it to derogatory and hurtful sentiments.

In Australia, majority of the population are aware of what the LGBTQ signifies, but a lot of unwarranted assumptions run rampant.

\section{$\underline{\text { Suggestions }}$}

Looking at the long list of challenges, India and Australia both need to introduce some changes to decrease discrimination against the LGBTQ community. 
1. Introduction of new, better laws in India- India can learn a lot from Australia in terms of additional laws and provisions that they have instated. The Indian judgement was very limited in scope and needs further additional laws and provisions. Marriage of same sex couples and adoption by them are some important milestones that India needs to achieve.

2. Inculcation of LGBTQ in school curriculum- This stigma about LGBTQ exists majorly because of lack of awareness, knowledge and exposure to those elements. Therefore, in context of that, India especially, needs to introduce curriculum in schools to educate children about it. Moreover, the middleaged strata of the society also need to be properly informed so that the youth of the LGBTQ community can safely come out to their parents without facing any harsh repercussions.

3. Develop a pro-LGBTQ environment- Another major challenge that the LGBTQ have to face is inclusion and isolation. In the past couple of years, many honest and open conversations have started and should further continue. Therefore, to combat isolation, a platform where the LTBTQ community can meet and talk about their experiences is very pertinent. For them to have a safe space to convey their feelings can be very influential in removing suicidal thoughts and can also promote a healthy mental state. Already, Pride Parades and a lot of different apps like Scruff, Grindr, etc are promoting a pro LGBTQ culture.

4. Initiatives to stop bullying- India and Australia both need to promote a healthy environment in schools and colleges. They need to take initiatives to stop bullying, verbal derogatory remarks and physical violence. Stringent rules and proper enforcement of rules can go a long way for the LGBTQ community to receive proper education.

5. Governmental intervention and Programmes- Government also needs to ensure programmes for the LGBTQ community, especially transgenders, to help them get jobs and break free from the vicious cycle. The government majorly needs to focus on rural areas as well, conduct workshops and meetings to make the people aware and also introduce measures to decrease honour killings and corrective therapies undertaken by their family members.

6. Construction of Shelters for the LGBTQ-Another solution could be construction of shelters for the LGBTQ community in rural areas so that they can have a safe space to regroup and avoid homelessness.

7. Free counselling sessions- Another major challenge is psychological stress. To combat that, the government could work towards having free counselling and therapy sessions for the LGBTQ community.

8. Training health staff on treating transgenders- The staff at the hospitals should also be properly trained on how to treat transgender people. The training could occur on a rolling basis until everyone is aware.

9. Transparent process for acquiring identity documents- A transparent and easy process should be available for the transgenders to obtain identity documents. Consideration towards including transgender as a gender in forms could go a long way in promoting a healthy environment.

In Australia, most of the above suggestions can work too. As compared to India, Australia is higher on the awareness scale but still, measures to stop bullying and promoting a pro-LGBTQ community can go a long way in furtherance of a brighter future.

\section{Conclusion}

As far as comparison between the historical background, the above information suggests that Australia got into the gay rights movement way before India. But it also suggests that India achieved the results faster. At present, in respect to laws concerning the LGBTQ community, Australia is ahead of India. But, in the process, both countries had to go through the same turbulent struggles, fraught with political divides and stigma. While India had to deal with the acceptance of various religions and cultures of gay rights movement, Australia had to deal with different with the difference in opinions of the ruling parties.

And as far as the challenges are concerned, from the information, it can bederived that both countries have their own set of problems. India has many more problems that Australia but that was to be expected. It can also be derived that a lot of problems are common to both India and Australia, though differing in degree. India decriminalized Section 377 just three years back and further changes will require some time. On the other hand, it has been quite some time since Australia legalized consensual sex between same-sex adults. And in that period of time, they have also legalized adoption and marriage between same-sex couples. Therefore, we can expect major changes in India in the coming years too. 


\section{$\underline{\text { References }}$}

1. ABC News (2017) Same-sex marriage bill passes House of Representatives, paving way for first gay weddings. Retrieved from https://www.abc.net.au/news/2017-12-07/same-sex-marriage-bill-passeshouse-of-representatives/9235560

2. Ben Winson (2016) A definitive timeline of LGBT+ rights in Australia. Retrieved from https://www.sbs.com.au/topics/pride/agenda/article/2016/08/12/definitive-timeline-lgbt-rights-australia

3. Beyond Blue (n.d.) Statistics. Retrieved from https://www.beyondblue.org.au/media/statistics

4. Council of Europe, (n.d) What is gender mainstreaming? Retrieved from https://www.coe.int/en/web/genderequality/what-is-gender-mainstreaming

5. Delhi High Court (2009) Naz Foundation v. Govt. of NCT of Delhi, 160 Delhi Law Times 277. Retrieved https://web.archive.org/web/20090826035913/http://lobis.nic.in/dhc/APS/judgement/02-072009/APS02072009CW74552001.pdf

6. Dr. Subhrajit Chatterjee (2018) Problems Faced by Transgender Community in India, IJCRT, Volume 6, Issue 1, page no. 671. Retrieved from https://ijcrt.org/papers/IJCRT1705102.pdf

7. GayCentre (n.d) What is LGBTQ? Retrieved from https://gaycenter.org/about/lgbtq/

8. Graeme Reid (2017) A Global Report Card on LGBTQ+ Rights for IDAHOBIT. Retrieved from https://www.hrw.org/news/2020/05/18/global-report-card-lgbtq-rights-idahobit\#

9. Human Rights (Sexual Conduct) Act (1994) - Commonwealth Consolidated Acts. Retrieved from Sect 4http://www6.austlii.edu.au/cgi-bin/viewdoc/au/legis/cth/consol_act/hrca1994297/s4.html

10. Liam Elphic (2019) Marriage equality was momentous, but there is still much to do to progress LGBTI+ rights in Australia. Retrieved form the Conversation- https://theconversation.com/marriageequality-was-momentous-but-there-is-still-much-to-do-to-progress-lgbti-rights-in-australia-110786

11. Malavika Rajkumar (2018) The Challenges faced by Transpersons in India. Retrieved from Mediumhttps://medium.com/one-future/the-challenges-faced-by-transpersons-in-india-fa46575ca14d

12. Mallikarjuna, K. G., and N. T. K. Naik. "Indicators of Women Economic Empowerment." International Journal of Humanities and Social Sciences (IJHSS) 3.3 (2014): 67-74.

13. Mint (2021) Being LGBT in India: Some home truths. Retrieved from https://www.livemint.com/Sundayapp/sAYrieZdZKEybKzhP8FDbP/Being-LGBT-in-India-Somehome-truths.html

14. Pundir, Pallavi (2018) I Am What I Am. Take Me as I Am. Retrieved from Vice Newshttps://www.vice.com/en/article/7xq5yd/i-am-what-i-am-take-me-as-i-am

15. Rajagopal, Krishnadas (2018) SC decriminalises homosexuality. Retrieved from The Hindu https://www.thehindu.com/todays-paper/sc-decriminalises-homosexuality/article24887363.ece

16. Rai, Anjana, and Jawaharlal Nehru. "POLITICAL EMPOWERMENT OF WOMEN IN INDIA: STATUS AND CHALLENGES." International Journal of Humanities and Social Sciences (IJHSS) 7 (2018): 9-18.

17. Santosh Behera, Bibhu, and Bibhuti Prasad Mohapatra. "A Gender Comparative Socio-Economic Study with Respect To Social Participation, Membership Status and Outward Orientation among the Farmers and Farmwomen in Keonjhar District of Odisha." International Journal of Environment, Ecology, Family and Urban Studies (IJEEFUS) 6.3 (2016): 91-102.

18. Sumadsad, Concepcion, and Ariel Tuazon. "gender and development (GAD) awareness in a higher education institution." International Journal of Educational Science and Research (IJESR) 6.3 (2016).

19. Sarmah, C. K. "Gender GAP in Assam: a Socio-Demographic Analysis." International Journal of Applied Mathematic \& Statistical Sciences, 5 (5), 4752 (2016).

20. Vijay, Swati, and SayaliGilbile. "A Study of Perception of Employees Regarding Workforce Diversity at Selected Educational Institutes in Pune City." International Journal of Business and General Management 7.3 (2018): 85-94.

21. Wikipedia (2020) LGBT history in Australia. Retrieved from https://en.wikipedia.org/wiki/LGBT_history_in_Australia\#: :text=In\%201994\%2C\%20the\%20Comm onwealth\%20passed,conduct\%20was\%20repealed\%20in\%20Tasmania.

22. Wikipedia (2021) Coming out. Retrieved from https://en.wikipedia.org/wiki/Coming_out

23. Wikipedia (2021) LGBT history in India. Retrieved from https://en.wikipedia.org/wiki/LGBT_history_in_India 